\title{
The automotive industry and the increasing relevance of a consumer perspective: a research agenda
}

\author{
Pietro Lanzini \\ Department of Management, \\ Università Ca' Foscari, \\ Cannaregio 873, 30121, Venezia, Italy \\ Email: lanzini@unive.it
}

\begin{abstract}
The deep transformations occurring in transports and mobility call for automakers and other actors in the automotive industry to gain further insights on the mechanisms underpinning behaviours of commuters, which represent the key-actor in determining the success or failure of any industrial initiative or public policy in the sector. The present article provides a detailed overview of the state-of-the-art of research on the determinants of car use, identifying relevant gaps of knowledge and advancing a research agenda to overcome the limitations of current studies hindering their effectiveness in providing a valuable informational background on which to build sound strategies.
\end{abstract}

Keywords: automotive industry; car use; consumer perspective; meta-analysis; mobility; research agenda.

Reference to this paper should be made as follows: Lanzini, P. (2018) 'The automotive industry and the increasing relevance of a consumer perspective: a research agenda', Int. J. Automotive Technology and Management, Vol. 18, No. 1, pp.46-58.

Biographical notes: Pietro Lanzini is an Assistant Professor at the Department of Management of Ca' Foscari University (Venice), where he gained his $\mathrm{PhD}$ in 2013. He obtained his Ms in Business Economics and a post-lauream Master cum laude at the Bocconi University (Milan), where he worked (2003-2009) at IEFE and SPACE research centres. He spent four months at the United Nations Headquarters in New York City (UNDESA), and one year at the University of Aarhus (Denmark). His research interests include consumer behaviour in the field of sustainability, with a focus on mobility and on spillover-related phenomena.

\section{Introduction: an evolving scenario for the automotive industry}

The automotive industry is expected to face profound transformations in its competitive environment over the next few years, so that the term shifting paradigm is often emphasised. Changes that are taking place are fast in pace and heterogeneous in nature (Aguiléra and Grébert, 2014), as they range from an evolution of the business ecosystem to the emergence of new institutional actors and policies automakers are now asked to interact and deal with. This article focuses on consumer behaviour in the field of 
mobility, an area that has been so far under-investigated though it bears the potential to provide a crucial informational background on which all involved actors (automakers in primis) could build their strategies. Indeed, gaining further insights on the topic would support the industry to direct effectively the behaviour of commuters, as to align it with corporate goals. After an introduction on the main trends that characterise the transport sector and the institutional framework that is developing at European level, the article provides an overview of the state of knowledge on modal choice research, proposing at once a research agenda to shed further light on such a crucial aspect.

The transport (and, more broadly speaking, the mobility) sector is today characterised by the intertwining effect of two overarching trends. On the one hand, transport activity is bound to increase over the next decades, both on global stage (thanks to the fast pace of motorisation in highly populated countries such as China, Brazil and India) and in Europe. In the EU, estimates suggest that by 2050 the growth in passenger and freight transport with respect to 2010 will reach an astonishing $42 \%$ and $60 \%$, respectively (European Commission, 2017). On the other hand, increasing demand is tackled by the awareness that current mobility patterns are not sustainable, given the negative effects on public health and the environment, especially in urban areas (Gärling and Friman, 2015). Specifically, air pollution represents a key aspect to be tackled, as transport is a crucial contributor of GHG emissions, second only to the energy sector (with private mobility being responsible for half of the overall transport related emissions) and it represents a social emergence given the high number of deaths linked with poor air quality (European Environment Agency, 2016). The situation is severe especially in urban areas, where three quarters of Europeans actually live and with such figure bound to increase in the near future.

Over the past decade, the EU adopted an active role in setting forth the necessary conditions for the shift to a new mobility paradigm, capable of ensuring all citizens the right to accessibility and freedom of movement while at once limiting the detrimental impacts on the environment and on health. Milestones of such effort are represented by the 2009 Action plan on urban mobility (European Commission, 2009), the 2011 White paper on transport (European Commission, 2011) or the 2013 Urban mobility package (European Commission, 2013a), which face a broad set of key-issues ranging from public policies at regional level to commuters' behaviours. A key concept for the achievement of sustainable urban transport systems is represented by sustainable urban mobility plans (SUMPs), representing "a strategic plan designed to satisfy the mobility needs of people and businesses in cities and their surroundings for a better quality of life. It builds on existing planning practices and takes due consideration of integration, participation and evaluation principles" (European Commission, 2013b).

The automotive industry itself is asked to propose new products based on technological innovations improving traditional dimensions such as safety and comfort, while curbing polluting emissions (Wells, 2010): often competition is based on the achievement of targets exceeding mere legal compliance with regulations and standards set forth by international bodies. While most of the times vehicles represent innovative and improved solutions within the dominant technological paradigm of internal combustion engines, the automotive industry is also introducing in the market products that refer to different paradigms; it is the case for instance of electric vehicles, that have a long track of holding promises of changing the shape of the industry, yet seem still far from a large-scale commercialisation phase (Hildermeier, 2016). 
Evolving patterns in legislation and technological innovation, with the rapid development of new technological trajectories that are still in a fluid phase and characterised by relative uncertainties, certainly represent crucial dimensions the automotive industry is required to deal with. In addition to these, a series of emerging socio-economic trends are already significantly affecting the overall competitive framework of the automotive industry, with the spread of sustainable mobility policies that merge with new lifestyles hindering the use of private cars. These changes might develop underneath the surface, yet bear the potential to exert a powerful influence on the industry. The concept itself of mobility is changing: how citizens (from now on, commuters) perceive mobility, what are they asking from a mobility system and how private car use fits in this new scenario. For instance, car use is experiencing a shift in perspective from ownership to availability (Tinnilä and Kallio, 2015). While in the past owning a car was conceived as a status symbol and an objective per-se, an increasing share of commuters show great interest for opportunities of using cars without owning them (car-sharing, ride-sharing, carpooling, etc.). Moreover, in many countries younger generations take the driving license (if at all) at a later age, since driving a car is not considered as essential as it was one generation ago.

In sum, albeit currently private cars dominate the panorama of individual transport, it is likely that their predominance will shrink as a consequence of changing commuters' behaviour and public policies aimed at energy efficiency and pollution reduction. The traditional view, suggesting that after market saturation car demand would settle relatively flat, has been indeed challenged in recent years by the emergence of the so-called peak car hypothesis: the possible structural decline of cars' demand deriving, among other factors, from the development of principles and policies for urban sustainable mobility (Stocchetti, 2013). The debate is still open and no general agreement has been reached on the issue; while there is evidence supporting the hypothesis (Metz, 2013), some scholars indeed deny the existence of peak car, claiming that the latter could affect only specific groups and areas, at the most (Le Vine and Jones, 2012).

Moreover, the use of car might follow different patterns from existing ones, given the growing propensity to surrogate car ownership with car availability; albeit this trend appears today to be limited to specific niches, all involved actors should carefully consider the possibility of the phenomenon to spread, especially if some conditions (such as the disruption of path dependencies or the overcoming of car related structures) will be met.

In such context, the understanding of the determinants of car use versus other travel mode choices is a crucial step in the roadmap to the establishment of innovative business models fitting the evolving relationship between carmakers and their final customers.

Indeed, the role of commuters is crucial as they represent the actor that defines the success or failure of any public policy or industrial initiative. Policy makers can implement SUMPs or build modern transport infrastructure and the automotive industry can propose technological innovations that curb air pollution and increase safety; yet, it is the single individual that will decide every day which type of transport mode to use (and how) for her daily commutes.

This article focuses on the domain of car use determinants as to identify the present limitations and knowledge gaps in the field, defining a research agenda capable of shedding light on the issue, thus providing a sound informational background based on which agents in the field (being them policy makers or industrial actors) can make adequate decisions and implement educated strategies. In order to do so, it is organised as 
follows. First, a brief overview of theoretical frameworks and empirical evidence in literature is presented; this will be mainly based on the results of two recent metaanalyses on the determinants of modal choice that synthesise the state of knowledge on the issue. Such evidence represents the basis for the second step, which consists of a discussion on the gaps in knowledge that still hinder a deep understanding of the real motives underpinning behaviours in the domain of mobility, which in turn is a prerequisite for the setting up and implementation of effective strategies both for policy makers and for industrial actors in the automotive sector.

\section{Investigating the determinants of car use: existing evidence}

Literature on the determinants of car use is vast; a consistent number of empirical investigations on the topic are rooted in environmental psychology research, as to shed light on the variables that determine whether individuals choose private car use (which is assumed to be intrinsically polluting) for their daily commute, or alternative and more sustainable transport modes, such as public transportation, cycling and so on. Indeed, gaining better insights on the behavioural and psychological correlates of modal choice is of great interest for the automotive industry: depending on what predictors emerge as salient in shaping commuter choices, different strategies can be envisaged as to convince people to adopt behaviours that are consistent with corporate goals. For instance, if environmental values emerge to be a predominant factor, the take-home message could be the necessity to invest in R\&D to achieve technological solutions that go beyond legal compliance with existing standards, proposing to prospective customers an offer that is focused on sustainability (and communicating it, effectively). On the other hand, if subjective norms emerge as a close antecedent of behaviours, communication strategies should be aimed at strengthening the social dimension of the offer, in terms of status, community, social value of private mobility and so on.

Research on the determinants of car use can be broadly categorised into two main branches, which are typical of studies on consumer behaviour in general. On the one hand, studies rooted in a rationalistic perspective suggesting that commuters choose whether (and to what extent) to use private cars as a consequence of a structured, deliberated cognitive process based on an aware consideration of available alternatives. On the other hand, studies stemming from a perspective based on the relevance of associations between specific cues and goal-oriented responses that develop in the automatic performance of a behaviour (thus, in the emergence of a habit).

The rationalistic perspective long dominated consumer behaviour literature; most of the popular theories adopted in studies on modal choice can be ascribed to such branch, like the theory of planned behaviour (TPB) (Ajzen, 1991), the norm-activation-model (NAM) (Schwartz, 1977) and the value-belief-norm theory (VBN) (Stern et al., 1999).

TPB has been successfully adopted in a broad set of behavioural research, including many studies on the determinants of car (non) use. It assumes that behaviours follow a deliberate cognitive process and have in intentions their closest antecedent. Intentions capture the motivational factors that influence actual behaviours and have in turn three main antecedents: attitudes, subjective norms and perceived behavioural control. Attitudes represent the generic predisposition of an individual towards a specific behaviour: they are based on the beliefs of outcomes associated with performing the 
behaviour and on the evaluation of whether such outcomes are positive or negative. Subjective norms reflect the social pressure experienced by individuals with respect to a specific behaviour. In the case of car use, people might keep in great consideration whether referents (families, peers, colleagues) would approve their use of a private car (or, alternatively, of other means of transportation) for commuting. Perceived behavioural control has been added to the original model of Fishbein and Ajzen's (1975) theory of reasoned action (TRA), which was based on attitudes and subjective norms, only. Following criticism with reference to TRA's unrealistic assumption that all behaviours are under volitional control, perceived behavioural control has been added as the element representing how easy or difficult we perceive a specific behaviour is to perform.

Another stream of research rooted in the rationalistic perspective is based on values and personal (or moral) norms. Values mirror the desirability of end states, which act as guiding principles shaping our behavioural patterns. For instance, if an individual holds universalistic values (Schwartz, 2012), it is likely that his commuting activities will be guided by the willingness to choose the transport mode that is more environment-friendly (hence, low-polluting cars or alternative means of transportation such as public transport). Similarly, personal norms reflect the perceived moral obligation to carry out an activity, or to refrain from doing so. According to NAM, personal norms get activated in individuals that are aware of the adverse consequences of (not) performing a behaviour (awareness of consequences) and that feel responsible for such negative outcome (ascription of responsibility). VBN incorporates NAM with the work of Schwartz on values and with the new ecological paradigm (NEP) (Dunlap and Van Liere, 1978). The latter is a measure of the endorsement of a pro-environmental world-view and it is based on a scale where respondents are asked to express their agreement with a battery of statements on the balance between individuals, society and the surrounding environment.

The second branch of research on the determinants of car use is based on the assumption that many behaviour are not guided by a rational and aware process, as they are the result of an automatic response to a recognised situation. Frequent behaviours that become habitual have been object of diverse literatures. In sociology, for instance, a popular stream of research stems from the theory of structuration (Giddens, 1984), which is based on the duality of structure and agency in driving social practices and behaviours. A cornerstone of the theory is so-called practical knowledge (PK), which in its tacit form implies that individuals automatically and unconsciously apply their knowledge as to perform actions in recognised and familiar contexts (Guzman, 2009). Similarly, in environmental psychology research (which represents the focus of the present article) habits represent "learned sequences of acts that have become automatic responses to specific cues and are functional in obtaining certain goals or end-states" [Verplanken and Aarts, (1999) p 104]. Stable contexts such as those typical of commuting activities (e.g., going to work every day, on the same route, at the same time, etc.) have been pinpointed as a crucial element for the development of habits. While habits are relegated to an ancillary role (if not neglected tot-court) in rationalistic models such as the TPB, there is now a growing literature that assumes they play a crucial role in determining behaviours, with the mobility domain making no exception.

Notwithstanding growing research on the topic, triggered by the relevance it bears for scholars and practitioners, the utility of emerging evidence from a practical standpoint has been long hindered by the heterogeneity of results in empirical investigations. To synthesise such vast yet difficult to handle body of evidence, two meta-analyses have been performed (Hoffmann et al., 2017; Lanzini and Khan, 2017) to illustrate which 
results are more robust and significant. These contributions come almost a decade after the work of Gardner and Abraham (2008), extending the dataset with recent empirical investigations and attempting at opening the black box of the variability in results, by means of heterogeneity analyses. Table 1 synthesises the main features of the two meta-analyses.

Table 1 Meta-analyses on travel mode choice

\begin{tabular}{lcc}
\hline & Hoffman et al. (2017) & Lanzini and Khan (2017) \\
\hline Number of studies & 43 & 58 \\
Geographic coverage & Europe 36; Australia 3; USA 3; & Europe 50; USA 3; Canada 2; \\
& Canada 1 & Taiwan 2; Japan 1 \\
Effect size & Correlation & Correlation \\
Heterogeneity & $\mathrm{X}^{2}$, I squared & I squared \\
Publication Bias & Egger's test, funnel plots & Failsafe n \\
Moderator analysis & Yes (exploratory) & Yes \\
\hline
\end{tabular}

The Lanzini and Khan (2017) meta-analysis confirms that, in accordance with the TPB framework, intentions represent the main antecedent of modal choice behaviours with a combined effect size (representing a sort of weighted average of the correlation between intention to drive a car and actual behaviour) of 0.825 . Past use and habits come second, with a combined effect size of 0.686 and 0.416 , respectively. According to Cohen (1988), combined effect sizes $>0.10,>0.30,>0.50$ and $>0.70$ qualify as small, medium, large and very large, respectively.

Also the other planned behaviour constructs (attitudes, subjective norms and PBC) have good predictive capability of car use, yet to a lesser extent compared to intentions, habits and past use. Moreover, it is interesting to point out how these determinants appear to be closer to behavioural intentions compared to actual behaviours (Gardner and Abraham, 2008), signalling a relevant intention-behaviour gap. The latter emerges as an interesting interpretation key also with reference to environmental variables such as values and concern for sustainability issues. Indeed, the meta-analysis confirms that these have strong predictive power with reference to behavioural intentions, yet they play a negligible role as antecedents of actual behaviours. The implications for policy are relevant, as initiatives focusing on the sustainability of the offer (public transportation, low-polluting cars and so on) "might fail in the end to lead to a concrete, effective behavioural shift" [Lanzini and Khan, (2017), p.20].

The heterogeneity analysis conducted in an attempt to explain the high variability across studies focused on five study characteristics: the sample, trip purpose, geographical location, study period and measurement of behaviours. The way behaviours are measured and operationalised is the factor affecting heterogeneity of results the most, followed by trip purpose and sample type. Other moderators emerged as scarcely significant (study period) or insignificant (location).

The Hoffmann et al. (2017) meta-analysis found that TPB and NAM are widely adopted frameworks, with TPB constructs having higher predictive capability compared to those pertaining to NAM. Consistently with Lanzini and Khan (2017), car use intentions are the best predictor of actual behaviours (combined effect size 0.50), though to a lesser extent compared to the former research. Similarly, intentions are followed by habits $(0.47$ or 0.38 , according to the specific measure of habits adopted) and by other 
TPB constructs such as attitudes $(0.22)$, subjective norms $(0.20)$ and PBC $(0.30$ or 0.39 , according to whether anomalous negative associations were removed or not).

As far as the NAM framework is concerned, only personal norms (that is, feelings of moral obligations not to drive cars) were found to have a sensible (negative) effect on car use $(-0.35)$, well above awareness of consequences $(-0.22)$ and ascription of responsibility $(-0.14)$.

Table 2 summarises the empirical evidence emerging from the two meta-analyses, illustrating the combined effect sizes from some crucial determinants of car use:

Table 2 Meta-analyses results

\begin{tabular}{lcc}
\hline Behavioural determinants & Hoffmann et al. (2017) & Lanzini and Khan (2017) \\
\hline Intentions - car use & 0.50 & 0.825 \\
Intentions - non-car use & -0.38 & -0.511 \\
Attitudes - car use & 0.22 & 0.406 \\
Attitudes - non-car use & -0.23 & -0.358 \\
Subjective norms - car use & 0.20 & 0.229 \\
Subjective norms - non-car use & -0.15 & -0.153 \\
PBC - car use & 0.39 & 0.270 \\
PBC - non-car use & -0.42 & -0.429 \\
Habits - car use & $0.38-0.47$ & 0.416 \\
Past car use - car use & - & 0.686 \\
Personal norms - car use & - & 0.362 \\
Personal norms - non-car use & -0.35 & -0.262 \\
Awareness of consequences - car use & -0.22 & -0.13 \\
Ascription of responsibility - car use & -0.14 & -0.144 \\
Altruistic values - car use & -0.32 & - \\
Environmental concern - car use & - & -0.195 \\
\hline
\end{tabular}

There is substantial agreement between the two meta-analyses as far as the main trends emerging are concerned. Both works suggest that TPB constructs and habits represent crucial building blocks of behavioural choices in the mobility domain, above other normative and value-related predictors. Habits indeed seem to be particularly relevant, given the context stability that often characterises the setting of commuting behaviours. The policy implications are relevant: efforts should be angled towards disrupting deeply rooted behavioural patterns as to substitute them with new ones, in line with the objectives of the agent. Acting on behaviours that are triggered by automatic responses represents a difficult task, as the strategies usually adopted to shape behavioural patterns based on aware cognitive processes are not effective. Verplanken and colleagues proposed solutions that stem from the assumption that alternatives and new information are more likely to be evaluated when context changes; if such habit discontinuity hypothesis (Verplanken and Wood, 2006) holds, implications for policy would be relevant, as the most effective interventions to change habits would be those performed in association with big changes in our daily lives, such as relocation or change of job (Verplanken et al., 2008). Many studies, acknowledging that behaviours are the result of a synergic effect of deliberate and non-deliberate factors, attempted at merging the two 
perspectives typically integrating habits within the TPB framework (Bamberg et al., 2003; Chen and Chao, 2011; Forward, 2014, Lo et al., 2016).

\section{The next steps: a research agenda for the future}

While the meta-analyses represent a step forward from the (vast yet) scattered empirical evidence on the determinants of car use, there are still limitations in current research that need to be addressed in order to gain better understandings on the topic. I hereby propose a research agenda for future studies, that would support actors in the mobility sector achieve their goals being them policy makers implementing effective sustainable mobility policies or industrial actors in the automotive industry.

While some aspects are broad and overarching as they refer to conceptual issues that affect the whole structure of researches on commuter behaviour, others are specific and methodological as they refer to operational issues that ought to be considered and dealt with. I hereby adopt an illustrative scheme that, stemming from overarching conceptual aspects, narrows down to methodological and operational issues, as the latter can be implemented only once the general structure of the research has been setup.

A first element to be considered when approaching researches on the determinants of car use is the fact that existing frameworks, albeit effective in analysing the main predictors of modal choice, focus on specific sets of variables, only. As such, they only cover part of the picture and they don't provide a broader and holistic perspective capable of considering heterogeneous variables whose interaction shapes behavioural patterns.

In a contribution on consumer behaviour, I propose a new interpretative framework for analysing behavioural determinants in sustainability-relevant domains such as mobility (Lanzini, 2017). I argue that a holistic approach should be adopted, breaking free from a simplistic view based on a single theoretical framework, since the complexity of the topic requires an overarching perspective based on a flexible approach. Future research should investigate car use analysing the role that both cognitive processes and habits exert on actual behaviours. These two, in turn, have sets of predictors that stem from an individual, a relational and a contextual sphere. Most existing frameworks focus on a limited set of such predictors. TPB, for instance, which represents the most widely adopted framework in car use research, focuses on the rationalistic element only. Even further developments of the original model, encompassing habits as a further predictor, do not grasp the complexity of the construct. Moreover, I argue that a flexible approach is required, insofar even within a specific behavioural domain (such as that of car use) there is no one-size-fits-all model that can be applied to every investigation or empirical setting: there are specific contextual factors that make some variables salient over others, so that it is up to the researcher to recognise which elements should be included in the model (since it would not be operationally feasible to put all variables from different streams of research in one single, elephantine model). For instance, automatic responses are likely to play a secondary role in studies on car use behaviour in tourism destinations (private car or car rental), where individuals are not likely to have time to develop deeply rooted habits; at the same time, habits are likely to play a prominent role in studies on commuter behaviour. In sum, there is no single theory that can stand alone in explaining why people decide to use private cars, or to what extent; on the contrary, adopting a 
tailor-made approach the educated researcher will pinpoint the set of variables on which to focus, based on the specific research at hand.

Consistently with the need to adopt a holistic perspective, which represents a sort of conceptual pre-requisite in conducting research on car use determinants, a crucial element is represented by the urge not to overlook the broader picture and the overarching changes and trends that are affecting transport and mobility. New perspectives of analysis are emerging, so that results of analyses on commuter behaviour can be fully understood only if investigated through a broader lens. The keys of interpretation themselves are changing, as new variables ought to be considered as to improve the predictive capability of existing frameworks and models. Among these, the time dimension should be considered as a priority. Interestingly, notwithstanding perceptions of travel time have been long considered an issue of interest in the literature on commuter behaviour, the topic has been under-investigated so far. To date, most research in the field of transportation and mobility is based on the assumption that the quicker the trip (or the commute), the better: time spent travelling, in other words, is considered to have no inherent value. The consequence of such a narrow interpretation of mobility is that policies and strategies are aimed at minimising the time that commuters spend on their daily travels, with little or no concern for how the travel time is spent. This view (which can be labelled as the speed paradigm) is likely to be replaced by the so-called productivity paradigm, which focuses on the experiential component of commuting (Gripsrud and Hjorthol, 2012), assuming that travel might also represent an opportunity to productively use time (for working, socialising and so on).

From an operational standpoint, the shift to the productivity paradigm means that the time dimension needs to be integrated in future research on the determinants of car use. Future studies should address research questions on how (dis)utility of travel time varies according to individual (socio-demographics, lifestyles, etc.) or contextual (mode shifts, comfort, safety, etc.) variables. Moreover, they should investigate how perceived (dis)utility of travel time varies according to the travel mode, inter-modularity, the number and type of mode changes and so on. For instance, do commuters prefer a longer trip on the same mode (entailing more comfort and productivity, since new technologies allow spending travel time productively, working or socialising) or a shorter trip, yet involving the discomfort of modal shifts? Emerging evidence would have relevant implications not only for policy makers dealing with the implementation of innovative and sustainable mobility plans, but also for businesses in the automotive sector and related services. Indeed, gaining insights on how travel time is perceived would provide automakers with useful recommendations on a further variable for innovative business models and on the role that such variable is able to exert in combination (and eventually trading-off) with traditional variables such as comfort, safety and so on.

Research on the topic could highly benefit from recent developments in ICT (Giannotti et al., 2016; Zhao et al., 2016). Indeed, big data technologies (e.g., tracking and tracing) allow to collect and process a huge bulk of data on commuters' behaviour in real-time, overcoming the drawbacks that hindered the effectiveness of traditional analyses, such as small sample sizes or the time and financial resources required to implement surveys and analyse data (Chen et al., 2016; Toole et al., 2015). Some of such technologies have now been in place for a few years, like the use of GPS data to estimate vehicular traffic velocities. However, the next leap is the adoption and improvement of such technologies beyond their traditional use: this could involve not only private cars but also other means of transportation, like for instance devices tracking cyclists' 
behaviours, as to analyse routes, speed, time and other travel-related information (Broach et al., 2012; Hood et al., 2011). Future research should build on the opportunities opened up by big data analysis, as to investigate a broad set of mobility related aspects, integrating traditional dimensions of analysis such as routes and speed with information regarding modal shifts, travel-experience satisfaction and so on. This would allow providing crucial feedback on how commuters perceive alternative travel options, on which all interested parties could build sound policies and strategies.

Other challenges, on the other hand, are more angled towards the methodological aspects of studies on car use. For instance, the meta-analyses identified operationalisation and measurement of basic constructs as a source of heterogeneity in the outcome across studies. It is the case, for instance, of the behaviour construct. This can be measured in surveys with questions referring to a quantitative specification of travel instances (e.g., how many times did you use a car over the past month?) or without such reference (e.g., how often do you use a car?): in the former situation we talk about actual behaviours, while in the latter we talk about typical behaviours. Measurement of typical vs. actual behaviours bears consequences for the comparability of results. Indeed, it is clear that while in typical behaviours there is a subjective component in the answer, this is absent in the operationalisation of behaviours according to the actual behaviour perspective. Let us consider the example of two commuters driving to go shopping ten times a month: whereas they will answer the same on an actual behaviour scale, it is possible that in typical behaviour surveys one might consider ten trips a month a lot and the other very little, so that the answers might be 'often' and 'rarely', respectively. Future research should converge towards recognised and widely agreed-upon standards, with guidelines that allow overcoming the fragmentation that hinders the comparability of different studies, thus the reliability of the informational background on which policy makers and industrial actors base their strategies.

Geographical location of studies emerged as the only moderator not explaining any heterogeneity in the results: "one possible speculation that should be addressed by future research is whether other variables might have better explanatory power compared to the country or the macro-region where the studies are performed" [Lanzini and Khan, (2017), p.22]. Indeed, it can be speculated that different variables overlooked by most existing research might have better explanatory power compared to the country where data are collected. It is reasonable to assume, for instance, that differences are more striking analysing rural vs. metropolitan areas: in terms of mobility features affecting commuters' choices, a large city is indeed likely to have more in common with other cities in different continents and cultural contexts, rather than with small villages only few miles away. While most studies in literature only provide minimal details about the location where data collection is performed, future research should be more rigorous in reporting detailed information on the issue.

In conclusion, the present article represents an attempt to overcome the fragmentation of existing literature on car use determinants, as shedding light on the topic would likely represent an effective support for automakers and other public and private actors in the automotive industry. The main limitations that have been identified as hindering factors for the effectiveness of current research can be categorised according to the following tripartition: overarching research approaches, overlooked dimensions of analysis and methodological aspects of empirical investigations. The steps ahead are challenging, as the proposed approaches envisaged by the research agenda are complex and requiring 
high analytical skills from practitioners. These will have for instance to be familiar both with the broad set of theoretical frameworks and inherent variables and with the specific case object of analysis and its peculiarities, as to single out those elements that need to be considered in the research on a case-by-case basis. Furthermore, some proposed solutions exceed the control of single researchers and practitioners: it is the case, for instance, of guidelines' setting for the homogenisation of different operational aspects of research (e.g., the operationalisation and measurement of behaviours), where the cooperation of other actors like international bodies is necessary. Yet, the prise is well worth the effort as gaining better insights on the determinants of commuters' behaviour represents a conditio sine qua non for the automotive industry to guide upcoming transformations in the sector, rather than facing its consequences as a passive spectator.

\section{References}

Aguiléra, A. and Grébert, J. (2014) 'Passenger transport mode share in cities: exploration of actual and future trends with a worldwide survey', International Journal of Automotive Technology and Management, Vol. 14, Nos. 3-4, pp.203-216.

Ajzen, I. (1991) 'The theory of planned behaviour', Organizational Behaviour and Human Decision Processes, Vol. 50, No. 2, pp.179-211.

Bamberg, S., Ajzen, I. and Schmidt, P. (2003) 'Choice of travel mode in the theory of planned behaviour: the roles of past behaviour, habit and reasoned action', Basic and Applied Social Psychology, Vol. 25, No. 3, pp.175-187.

Broach, J., Dill, J. and Gliebe, J. (2012) 'Where do cyclists ride? A route choice model developed with revealed preference GPS data', Transportation Research Part A: Policy and Practice, Vol. 46, No. 10, pp.1730-1740.

Chen, C.F. and Chao, W.H. (2011) 'Habitual or reasoned? Using the theory of planned behaviour, technology acceptance model and habit to examine switching intentions toward public transit', Transportation Research Part F: Traffic Psychology and Behaviour, Vol. 14, No. 2, pp.128-137.

Chen, C., Ma, J., Susilo, Y., Liu, Y. and Wang, M. (2016) 'The promises of big data and small data for travel behavior (aka human mobility) analysis', Transportation Research Part C: Emerging Technologies, Vol. 68, pp.285-299.

Cohen, J. (1988) Statistical Power Analysis for the Behavioural Sciences, 2nd ed., Hilsdale, Routledge, NJ.

Dunlap, R.E. and Van Liere, K.D. (1978) 'The 'new environmental paradigm", The Journal of Environmental Education, Vol. 9, No. 4, pp.10-19.

European Commission (2009) Action Plan on Urban Mobility, Brussels.

European Commission (2011) Roadmap to a Single European Transport Area - Towards a Competitive and Resource Efficient Transport System, White Paper.

European Commission (2013a) Together Towards Competitive and Resource-Efficient Urban Mobility, Communication from the Commission to the European Parliament, the Council, the European Economic and Social Committee and the Committee of the Regions, Brussels.

European Commission (2013b) Guidelines - Developing and Implementing a Sustainable Urban Mobility Plan, European Platform on Sustainable Urban Mobility Plans, Brussels.

European Commission (2017) Europe on the Move - An Agenda for a Socially Fair Transition Towards Clean, Competitive And Connected Mobility For All, Communication from the Commission to the European Parliament, the Council, the European Economic and Social Committee and the Committee of the Regions, Brussels.

European Environment Agency (2016) Air Quality in Europe, Report 28/2016. 
Fishbein, M. and Ajzen, I. (1975) Belief, Attitude, Intention and Behaviour: An Introduction to Theory and Research, Addison-Wesley, Reading, MA.

Forward, S.E. (2014) 'Exploring people's willingness to bike using a combination of the theory of planned behavioural and the transtheoretical model', Revue Européenne de Psychologie Appliquée/European Review of Applied Psychology, Vol. 64, No. 3, pp.151-159.

Gardner, B. and Abraham, C. (2008) 'Psychological correlates of car use: a meta-analysis', Transportation Research Part F: Traffic Psychology and Behaviour, Vol. 11, No. 4, pp.300-311.

Gärling, T. and Friman, M. (2015) 'Unsustainable travel becoming (more) sustainable', Handbook of Research on Sustainable Consumption, p.163, Edward Elgar Publishing, Cheltenham, UK.

Giannotti, F., Gabrielli, L., Pedreschi, D. and Rinzivillo, S. (2016) Understanding Human Mobility with Big Data, in Solving Large Scale Learning Tasks, Challenges and Algorithms, pp.208-220, Springer International Publishing, Switzerland.

Giddens, A. (1984) The Constitution of Society: Outline of the Structuration Theory, Polity, Cambridge.

Guzman, G. (2009) 'What is practical knowledge?', Journal of Knowledge Management, Vol. 13, No. 4, pp.86-98.

Gripsrud, M. and Hjorthol, R. (2012) Working on the train: from 'dead time' to productive and vital time', Transportation, Vol. 39, No. 5, pp. 941-956.

Hildermeier, J. (2016) 'Which role should the electric car play in Europe's cities? An analysis of publicly funded demonstration projects 2007-2013', International Journal of Automotive Technology and Management, Vol. 16, No. 1, pp.90-107.

Hoffmann, C., Abraham, C., White, M.P., Ball, S. and Skippon, S.M. (2017) 'What cognitive mechanisms predict travel mode choice? A systematic review with meta-analysis', Transport Reviews, Vol. 37, No. 5, pp.1-22.

Hood, J., Sall, E. and Charlton, B. (2011) 'A GPS-based bicycle route choice model for San Francisco, California', Transportation Letters, Vol. 3, No. 1, pp.63-75.

Lanzini, P. (2017) Responsible Citizens and Sustainable Consumer Behaviour. New Interpretative Frameworks, Taylor \& Francis, Routledge.

Lanzini, P. and Khan, S.A. (2017) 'Shedding light on the psychological and behavioral determinants of travel mode choice: a meta-analysis', Transportation Research Part F: Traffic Psychology and Behaviour, Vol. 48, pp.13-27.

Le Vine, S. and Jones, P. (2012) One the Move: Making Sense of Car and Rail Travel Trends in Britain, RAC Foundation, London, UK.

Lo, S.H., van Breukelen, G.J., Peters, G.J.Y. and Kok, G. (2016) 'Commuting travel mode choice among office workers: comparing an extended theory of planned behaviour model between regions and organizational sectors', Travel Behaviour and Society, Vol. 4, pp.1-10.

Metz, D. (2013) 'Peak car and beyond: the fourth era of travel', Transport Reviews, Vol. 33, No. 3, pp.255-270.

Schwartz, S.H. (1977) 'Normative influences on altruism', Advances in Experimental Social Psychology, Vol. 10, pp.221-279.

Schwartz, S.H. (2012) 'An overview of the Schwartz theory of basic values', Online Readings in Psychology and Culture, Vol. 2, No. 1, p.11.

Stern, P.C., Dietz, T., Abel, T., Guagnano, G.A. and Kalof, L. (1999) 'A value-belief-norm theory of support for social movements: the case of environmentalism', Human Ecology Review, Vol. 6, No. 2, pp.81-97.

Stocchetti, A. (2013) 'Are carmakers ready for the 'peak car'?', in Stocchetti, A., Trombini, G. and Zirpoli, F. (Eds.): Automotive in Transition. Challenges for Strategy and Policy, Edizioni Ca' Foscari, Venezia. 
Tinnilä, M. and Kallio, J. (2015) 'Impact of future trends on personal mobility services', International Journal of Automotive Technology and Management, Vol. 15, No. 4, pp.401-417.

Toole, J.L., Colak, S., Sturt, B., Alexander, L.P., Evsukoff, A. and González, M.C. (2015) 'The path most traveled: travel demand estimation using big data resources', Transportation Research Part C: Emerging Technologies, Vol. 58, pp.162-177.

Verplanken, B. and Aarts, H. (1999) 'Habit, attitude and planned behaviour: is habit an empty construct or an interesting case of goal-directed automaticity?', European Review of Social Psychology, Vol. 10, No. 1, pp.101-134.

Verplanken, B. and Wood, W. (2006) 'Interventions to break and create consumer habits', Journal of Public Policy \& Marketing, Vol. 25, No. 1, pp.90-103.

Verplanken, B., Walker, I., Davis, A. and Jurasek, M. (2008) 'Context change and travel mode choice: combining the habit discontinuity and self-activation hypotheses', Journal of Environmental Psychology, Vol. 28, No. 2, pp.121-127.

Wells, P. (2010) 'Sustainability and diversity in the global automotive industry', International Journal of Automotive Technology and Management, Vol. 10, Nos. 2-3, pp.305-320.

Zhao, K., Tarkoma, S., Liu, S. and Vo, H. (2016) 'Urban human mobility data mining: an overview', in Big Data, 2016 IEEE International Conference on Big Data, December, IEEE, Washington DC, USA, pp.1911-1920. 